\title{
Molecular Characterization of Recombinant Strains of Potato virus $Y$ From Saudi Arabia
}

Mohamad Chikh-Ali, Hayam Alruwaili, and Dalton Vander Pol, Department of Plant, Soil, and Entomological Sciences, University of Idaho, Moscow, ID 83844; and Alexander V. Karasev, Department of Plant, Soil, and Entomological Sciences, and Bioinformatics and Computational Biology Program, University of Idaho, Moscow, ID 83844-2339

\begin{abstract}
Chikh-Ali, M., Alruwaili, H., Vander Pol, D., and Karasev, A. V. 2016. Molecular characterization of recombinant strains of Potato virus $Y$ from Saudi Arabia. Plant Dis. 100:292-297.

Potato virus $Y$ (PVY) exists as a complex of strains, many of which are recombinants. The practical importance of PVY recombinant strains has increased due to their ability to induce potato tuber necrotic ring spot disease (PTNRD) that seriously affects tuber quality. In Saudi Arabia, potato production has increased fivefold during the last three decades, reaching 460,000 tons per year. Although PVY has been reported as one of the main viruses affecting potatoes, no information is available on PVY strains circulating in the country. In August 2014, a survey was conducted in a seed potato field at Al-Jouf, Saudi Arabia. PVY-positive samples selected based on visual symptoms and serological reactivity were subjected to strain typing using multiplex RT-PCR assays and were determined to represent recombinant PVY strains. Whole genome sequences were determined for two

representative isolates, $\mathrm{S} 2$ and $\mathrm{S} 9$, through direct sequencing of a series of overlapping RT-PCR fragments for each isolate, and found to represent strains PVY-NE11 and PVYZ (SYR-III), respectively. One of the recombinant types, SYR-III, was previously found in nearby Syria and Jordan, but the second recombinant, PVY-NE11, was found before only in the United States. Both recombinants, PVY-NE11 and SYRIII, were previously found associated with PTNRD and thought to be rare. The current identification of PVY-NE11 and SYR-III in seed potato in a new geographic region suggests that these recombinants may not be as rare as previously believed. This is the first report on the occurrence of recombinant strains of PVY in potato in Saudi Arabia, and the first report on the PVY-NE11 strain of PVY found in potato outside of the United States.
\end{abstract}

In Saudi Arabia, potato production is carried out under irrigation in two growing seasons, the spring and the fall. Potato is produced for fresh market and for processing into chips. Seed potatoes for the spring growing season ("Elite Class") are imported from several European suppliers located in the Netherlands, the United Kingdom, and France. Potato production of the spring growing season that is certified as seed potato is planted in the following fall season to produce "A Class" seed potatoes. In 2013, the main potato producing areas in Saudi Arabia were Al-Jouf, Hail, Tabuk, Qasim, Riyadh, Hofuf, and Najran (Fig. 1), with a total production area of 17,500 ha and a total production of 460,000 tons per year of which 45,500 tons were seed potatoes (FAOSTAT 2015).

Potato virus $Y(\mathrm{PVY})$ is the type species of the genus Potyvirus, family Potyviridae, the second largest family of plant viruses (Adams et al. 2012). PVY is the most economically important virus infecting potato crops worldwide, affecting both tuber yield and quality all over the world (Gray et al. 2010; Karasev and Gray 2013; Scholthof et al. 2011; Singh et al. 2008). It is also associated with major diseases in other crops, like pepper and tomato (Kerlan and Moury 2008). PVY exists as a complex of strains and variants that produce a range of symptoms in different hosts (Karasev and Gray 2013; Singh et al. 2008). Potato tuber necrotic ringspot disease (PTNRD) was found to be associated predominantly with recombinant PVY strains (Beczner et al. 1984; LeRomancer et al. 1994; Lorenzen et al. 2008), although it was later demonstrated to be caused by other, non-recombinant strains as well (Gray et al. 2010). Because of PTNRD and its effect on tuber quality, recombinant strains of PVY attracted significant attention, and their incidence and geographical distribution in potato producing areas have been of concern in the last few years

Corresponding author: Alexander V. Karasev, E-mail: akarasev@uidaho.edu Accepted for publication 17 June 2015.

http://dx.doi.org/10.1094/PDIS-05-15-0562-RE

(C) 2016 The American Phytopathological Society
(Anfoka et al. 2014; Boukhris-Bouhachem et al. 2008; Chikh Ali et al. 2010a; Djilani-Khouadja et al. 2010; Galvino-Costa et al. 2012a, b; Gray et al. 2010; Lorenzen et al. 2006a).

$\mathrm{PVY}$ have been classified into $\mathrm{PVY}^{\mathrm{O}}, \mathrm{PVY}^{\mathrm{C}}, \mathrm{PVY}^{\mathrm{N}}, \mathrm{PVY}^{\mathrm{Z}}$, and $\mathrm{PVY}^{\mathrm{E}}$ strains, based on reactions in potato cultivars carrying the resistance genes $N y_{t b r}, N c_{t b r}$, and $N z_{t b r}$, and in tobacco (Nicotiana tabacum L.; Chikh-Ali et al. 2014; Jones 1990; Karasev and Gray 2013; Kerlan et al. 1999; Singh et al. 2008). In the most recent classification, $\mathrm{PVY}$ isolates were divided into nine strains, $\mathrm{PVY}^{\mathrm{O}}, \mathrm{PVY}^{\mathrm{C}}$, $\mathrm{PVY}^{\mathrm{N}}, \mathrm{PVY}^{\mathrm{Z}}, \mathrm{PVY}^{\mathrm{E}}, \mathrm{PVY}^{\mathrm{N}-\mathrm{Wi}}, \mathrm{PVY}^{\mathrm{N}: \mathrm{O}}, \mathrm{PVY}^{\mathrm{NA}-\mathrm{N}}$, and PVYNE11 (Karasev and Gray 2013). PVYZ ${ }^{\text {PVY }}{ }^{\mathrm{E}}, \mathrm{PVY}^{\mathrm{N}-\mathrm{Wi}}, \mathrm{PVY}^{\mathrm{N}: \mathrm{O}}$, and PVY-NE11 are recombinant strains with different recombinant structures and parental sequences represented most often by $\mathrm{PVY}^{\mathrm{O}}$ and $\mathrm{PVY}^{\mathrm{N}}$, but sometimes by unknown parents, like PVY-NE11 (reviewed in Karasev and Gray 2013). The strain PVYZ, which triggers the resistance gene $N z_{t b r}$, comprises several diverse recombinants (Karasev and Gray 2013) designated as PVYZ ${ }_{-N T N}$ (Kerlan et al. 2011) and PVYNTN-NW (Chikh Ali et al. 2010a); PVY ${ }^{\text {NTN-NW }}$ recombinant, in turn, was further divided into three subtypes, SYR-I, SYR-II, and SYR-III (Chikh Ali et al. 2010a). All the recombinant types compiled into the $\mathrm{PVY}^{\mathrm{Z}}$ strain are composed of $\mathrm{PVY}^{\mathrm{O}}$ and $\mathrm{PVY} \mathrm{Y}^{\mathrm{N}}$ parental sequences, and have two main conserved recombinant junctions (RJs), RJ2 and RJ3; they differ, however, in the presence and positions of other recombinant junctions (see Karasev and Gray 2013). Most of the recombinants of PVY, including PVY $^{\mathrm{Z}}$-NTN, PVYE, PVY ${ }^{\mathrm{NTN}-N W}$, and PVY-NE11, caused PTNRD (Chikh Ali et al. 2010a; Galvino-Costa et al. 2012a; Karasev and Gray 2013; Kerlan et al. 2011; Lorenzen et al. 2008).

In the past, surveys reported PVY as one of the main viruses infecting potatoes in Saudi Arabia (Al-Saikhan et al. 2014; Al-Shahwan et al. 1997; Sabir 2012). For instance, Al-Shahwan et al. (1997) detected PVY in 20 to $63 \%$ of potato samples collected from two main potato production areas in the north of Saudi Arabia, Tabuk and Hail, from both spring and fall growing seasons. However, PVY strain composition in potato production areas has not been studied in Saudi Arabia. In neighboring countries, with similar potato production cycles, PVY population structure was studied in Syria and Jordan, 
where recombinants such as PVY ${ }^{\mathrm{NTN}-N W}$ (SYR-I, -II, and -III), $\mathrm{PVY}^{\mathrm{NTN}}$, and PVY ${ }^{\mathrm{N}-\mathrm{Wi}}$ were reported as dominant (Anfoka et al. 2014; Chikh Ali et al. 2010a). In Tunisia, a nearby Mediterranean country, PVY population was reported to be dominated by PVYNTN with few exceptions belonging to $\mathrm{PVY}^{\mathrm{N}}$ and $\mathrm{PVY}^{\mathrm{O}}$ (BoukhrisBouhachem et al. 2008; Djilani-Khouadja et al. 2010). Here, we report on the identification and characterization of nine recombinant PVY isolates from Saudi Arabia, and, for the first time, on the occurrence of significant recombinants of PVY, namely PVY-NE11 and SYR-III, in the country.

\section{Material and Methods}

Sample collection. A 25-ha seed potato field planted with the potato cultivar Hermes was sampled in August 2014, in the beginning of the fall growing season. The field was located near Al Jouf, Saudi Arabia, and belonged to the Al Jouf Agricultural Development Co. Plants showing virus-like symptoms of mosaic and crinkling were initially tested with the general PVY immuno-strip test (Agdia, Elkhart, IN) and PVY-positive samples were printed on FTA Classic Cards (Whatman, United Kingdom) according to the manufacturer's instructions. The cards were dried at room temperature for $1 \mathrm{~h}$, sealed in paper envelopes with silica gel, and shipped to the University of Idaho laboratory for further analysis.

RNA extraction, RT-PCR, and sequencing. RNA was extracted from FTA cards according to the method of Ndunguru et al. (2005). RNA pellets were dissolved in $30 \mu \mathrm{l}$ nuclease-free water, heated at $65^{\circ} \mathrm{C}$ for $5 \mathrm{~min}$, and then chilled on ice for $3 \mathrm{~min}$. Reverse transcription (RT) was done according to the method of Chikh-Ali et al. (2013). For strain identification, two different multiplex RT-PCR assays reported by Lorenzen et al. (2006b) and Chikh Ali et al. (2010b) were performed with a slight modification. The multiplex RT-PCR (Chikh Ali et al. 2010b) was modified by replacing the primer n7577 with a new primer (n7892: 5'-CTCAACTCCAGATGGAA CAATTGTC-3'). This resulted in two shorter PCR products, 992 and $761 \mathrm{bp}$, replacing the 1,307 and 1,076 bp products, respectively, in the original protocol (Chikh Ali et al. 2010a). Control isolates representing nine strains of PVY and additional recombinant variants were from the laboratory collection (Chikh-Ali et al. 2013).

Two of the nine samples, S2 and S9, were selected for whole genome sequencing. The whole genome sequencing was performed directly on a series of overlapping PCR fragments amplified on cDNA synthesized from the S2 and S9 samples using SYR-III-L4 and NE11 specific primers, respectively, as described in Karasev et al. (2011). Successfully amplified PCR products were treated with Exosap-It (Affymetrix, Cleveland, $\mathrm{OH}$ ) and submitted for Sanger sequencing to Genewiz, Inc. (South Plainfield, NJ). Individual sequence reads were assembled using the SeqMan program of the Lasergene 9 Suite (DNASTAR). The whole genome sequences for isolates $\mathrm{S} 2$ and $\mathrm{S} 9$ have been deposited in the GenBank database under the accession numbers KP793715 and KP793716, respectively.

Sequence analysis. Sequence analysis was carried out using the SeqMan Pro software (DNA Star; DNASTAR, Madison, WI). For the multiple alignment, the program CLUSTAL X ver. 1.81 (Thompson et al. 1997) was used with the default parameters. Sequence identity was checked using the BLAST program provided by the National Center for Biotechnology Information (NCBI). Alignments were conducted based on the whole genome of representative isolates of PVY strains and variants: $\mathrm{PVY}^{\mathrm{N}}, \mathrm{PVY}^{\mathrm{NA}-\mathrm{N}}, \mathrm{PVY}^{\mathrm{N}-\mathrm{Wi}}, \mathrm{PVY}^{\mathrm{N}: \mathrm{O}}$, PVYNTN, PVY-NE11, PVYNTN-NW (SYR-I, -II, and -III), PVYO', and $P V Y^{C}$. The aligned sequences were checked for recombination, using RDP (Martin and Rybicki 2000), GENECONV (Sawyer 1999), BOOTSCAN (Salminen et al. 1995), MAXCHI (MaynardSmith 1992), CHIMAERA (Posada and Crandall 2001), 3Seq (Boni et al. 2007), and SiScan (Gibbs et al. 2000) methods in RDP4 Beta3 software (Martin et al. 2005). The analyses in RDP4 Beta3 package were done using default settings and a Bonferroni-corrected $P$ value cut off of 0.05 . Only recombination points detected by more than four methods in the RDP4 Beta3 program were taken into consideration. Phylogeny inference was conducted using the neighbor joining (NJ) method implemented in the program MEGA version 4 (Tamura et al.
2007) with 1,000 bootstrap replicates. Branches with bootstrap values less than $70 \%$ were collapsed.

\section{Results}

A seed field of potato cv. Hermes was visually assessed for mosaic symptoms, and estimated to have ca. 3 to $5 \%$ of symptomatic plants. Fifteen leaf samples were collected exhibiting various degrees of mosaic and crinkling, and subjected to the general PVY testing using the PVY-specific immunostrips (Agdia). Nine samples were found PVY-positive, producing two distinct bands on the test strip, and these samples were applied to the FTA Classic Cards (Whatman) for further characterization to strain.

RT-PCR assay. When all nine PVY-positive samples were subjected to the multiplex RT-PCR assay developed by Lorenzen et al. (2006b), six samples produced two bands of 181 and $452 \mathrm{bp}$, one sample produced a single band of $328 \mathrm{bp}$, and two samples produced a single band of $181 \mathrm{bp}$, suggesting PVY ${ }^{\mathrm{NTN}}$ isolates in six samples and PVYNA-N in one (summarized in Table 1). In the multiplex PCR assay of Chikh Ali et al. (2010b), all samples produced PVY-specific bands (Fig. 2): three samples produced a band of $441 \mathrm{bp}$, two samples produced three bands of 278,441 , and $761 \mathrm{bp}$, and three samples produced two bands of 278 and $441 \mathrm{bp}$. A single 633-bp band was amplified from one sample (summarized in Table 1). Hence, all nine samples were determined to contain recombinant isolates of PVY - five were identified as SYR-III type, one as a NE-11 type, and three as possible SYR, N-Wi, or NTN type based on the inconclusive band pattern revealed in the Chikh-Ali et al. (2013) assay.

Sequencing and sequence analysis. Two samples, S2 (typed as SYR-III) and S9 (typed as PVY-NE11) were selected for whole genome sequencing as representative isolates. The sequences of their nearly complete genomes were determined by direct sequencing of overlapping RT-PCR fragments, and were found to be 9,511 nt for $\mathrm{S} 2$ and 9,536 nt for S9, excluding poly(A) and the extreme 5 -terminal sequences. Both genomes coded for an open reading frame of 3,061 amino acids. S2 shared the highest identity (99.4\%) with the isolate SYR-III-L4 (AB461454) reported from Syria, and $98.4 \%$ with SYR-II-DrH (AB461453) also reported from Syria (Chikh Ali

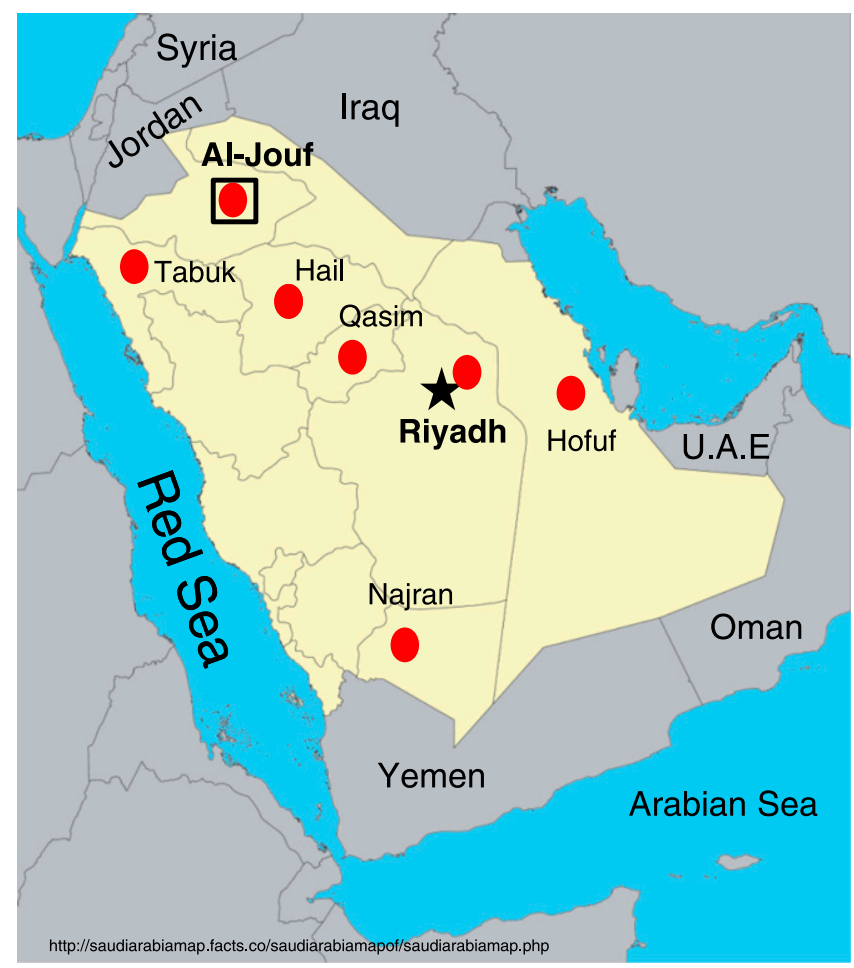

Fig. 1. Map of Saudi Arabia showing the location of Al-Jouf (marked with a rectangle) where PVY isolates were collected. Red circles with corresponding names refer to main potato production areas in Saudi Arabia. 
Table 1. Strain identification of Potato virus $Y$ (PVY) isolates collected from a potato field in Saudi Arabia using multiplex RT-PCR assays ${ }^{\text {a }}$

\begin{tabular}{|c|c|c|c|c|c|c|}
\hline Sample & $\mathbf{P C R}^{\mathbf{b}}$ amplicons & ID-Lorenzen ${ }^{b}$ & PCR $^{c}$ amplicons & ID-Chikh-Ali ${ }^{c}$ & Final ID & Recombination sites (nucleotide position) \\
\hline $\mathrm{S} 1$ & $181 / 452$ & NTN & $278 / 441$ & SYR-III? & SYR-III & \\
\hline $\mathrm{S} 2$ & $181 / 452$ & NTN & $278 / 441 / 761$ & SYR-III & SYR-III & P1(686), P3 (2415), VPg (5833), NIb (8426) \\
\hline $\mathrm{S} 3$ & $181 / 452$ & NTN & 441 & $?$ & NTN/SYR & \\
\hline S4 & $181 / 452$ & NTN & $278 / 441$ & SYR-III? & SYR-III & \\
\hline S5 & $181 / 452$ & NTN & $278 / 441 / 761$ & SYR-III & SYR-III & \\
\hline S6 & 181 & $?$ & 441 & $?$ & $?$ & \\
\hline S7 & $181 / 452$ & NTN & $278 / 441$ & SYR-III? & SYR-III & \\
\hline S8 & 181 & $?$ & 441 & $?$ & $?$ & \\
\hline S9 & 328 & NA-N & 633 & NE11 & NE11 & HC-Pro (2009), P3 (2489) \\
\hline NE-11 & 328 & NA-N & 633 & NE11 & NE11 & HC-Pro (2009), P3 (2489) \\
\hline SYR-III-1 & $181 / 452$ & NTN & $278 / 441 / 761$ & SYR-III & SYR-III & P1(686), P3 (2415), VPg (5833), NIb (8426) \\
\hline
\end{tabular}

a NE-11 and SYR-III-1 are reference isolates of PVY strains PVY-NE11 and SYR-III, respectively, which are maintained with PVY isolate collection of the University of Idaho.

b According to Lorenzen et al. (2006b).

c According to Chikh Ali et al. (2010b and 2013).

A

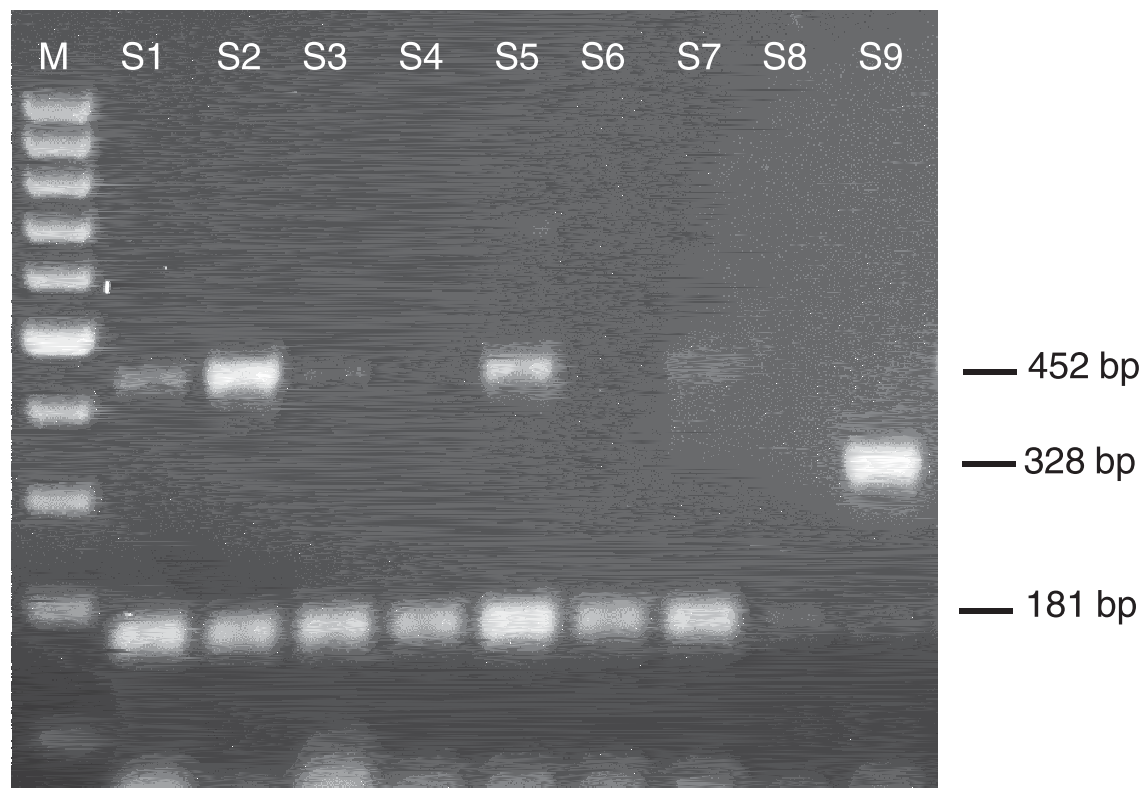

B

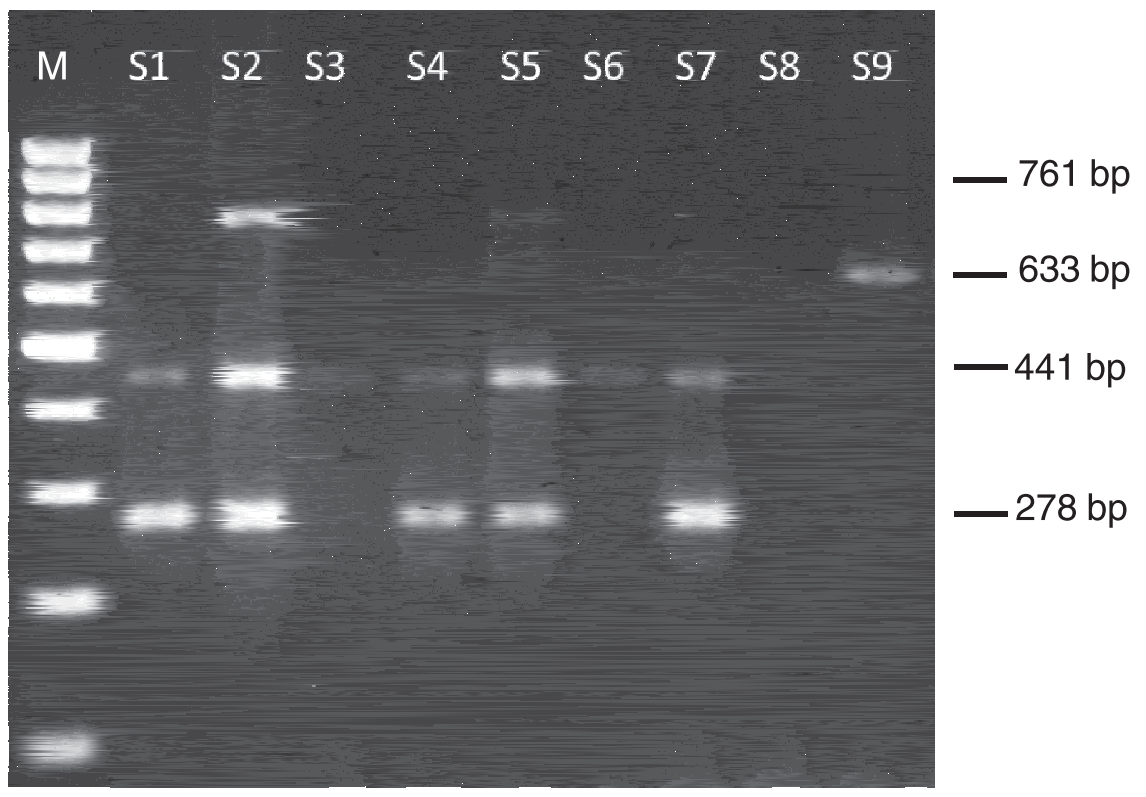

Fig. 2. RT-PCR assays for the identification of PVY isolates collected from a potato field from Saudi Arabia. Nine individual PVY-positive samples selected based on immunostrip reactivity are labeled S1 through S9. A, results of multiplex RT-PCR assay according to Lorenzen et al. (2006b). B, results of multiplex RT-PCR assay according to Chikh Ali et al. (2010b). Positions and sizes of the characteristic PCR products are indicated; M indicates the lane for size markers. 
et al. 2010a). Isolate S9 shared the highest identity (99.8\%) with the isolate NE-11 reported from the United States (DQ157180; Lorenzen et al. 2008) and with the Kalimeris indica isolate ME-162 reported from China (JQ971975; Wang et al. 2012) followed by $98.4 \%$ identity to the isolate ID20 reported from the United States (HQ912867; Karasev et al. 2011).

In the recombination analysis, $\mathrm{S} 2$ and $\mathrm{S} 9$ had identical recombination structures with isolates SYR-III-L4 and NE-11, respectively (Chikh Ali et al. 2010a; Lorenzen et al. 2008; see Fig. 3). The first recombination event in S2 (686-2415, Fig. 3) was detected by $P$ values using RDP $\left(1.679 \times 10^{-120}\right)$, GENECONV $\left(2.876 \times 10^{-113}\right)$, BootScan $\left(1.195 \times 10^{-119}\right)$, MaxChi $\left(\mathrm{M} ; 1.026 \times 10^{-27}\right)$, Chimaera $\left(1.274 \times 10^{-24}\right)$, 3SEquation $\left(1.264 \times 10^{-215}\right)$, and SiScan $(5.361 \times$ $\left.10^{-49}\right)$. The second recombination event in S2 (5833-8426; Fig. 3) was detected by $P$ values using RDP $\left(2.938 \times 10^{-129}\right)$, GENECONV $\left(4.907 \times 10^{-115}\right)$, BootScan $\left(6.852 \times 10^{-126}\right)$, MaxChi $(9.682 \times$ $\left.10^{-48}\right)$, Chimaera $\left(7.517 \times 10^{-40}\right)$, 3SEquation $\left(3.346 \times 10^{-227}\right)$, and SiScan $\left(1.218 \times 10^{-54}\right)$. S9 had a single recombination event (2009-2489; Fig. 3), which was detected by $P$ values using RDP $\left(1.232 \times 10^{-10}\right)$, GENECONV $\left(7.649 \times 10^{-08}\right)$, MaxChi $(6.003 \times$ $\left.10^{-06}\right)$, 3SEquation $\left(8.426 \times 10^{-12}\right)$, and SiScan $\left(1.029 \times 10^{-03}\right)$. The genome of $\mathrm{S} 2$ had $\mathrm{O}$ and $\mathrm{N}$ sequences identified as parents, while S9 had N and NA-N as parents for the first 2,489 nt of the genome and the rest of the genome originated from an unknown parent. When subjected to phylogenetic analysis together with representatives from major recombinant and non-recombinant lineages of PVY strains, S2 grouped closely with SYR-III-L4 while S9 was grouped closely to NE-11 and was placed in an "NE-11" subcluster at an intermediate position between $\mathrm{N}$ and NA-N (Fig. 4).

\section{Discussion}

Potato production in Saudi Arabia has increased from about 90,000 tons in 1990 (Al-Shahwan et al. 1997) to about 460,000 tons in 2013 (FAOSTAT 2015). With the continuous import of seed potatoes and the dramatic increase of potato production, the importance of potato virus diseases is also expected to increase. Several surveys reported PVY as the main virus infecting potatoes in Saudi Arabia (Al-Saikhan et al. 2014; Al-Shahwan et al. 1997; Sabir 2012), yet no identification or characterization of PVY strains in the country have been reported. Several partial sequences of the capsid protein (CP) area were reported for a few PVY isolates (Al-Saikhan et al. 2014; Sabir 2012), but these were not sufficient to determine the strain type due to the complex recombination structure of PVY strains (Karasev and Gray 2013). In the current study, two PVY recombinant types, SYR-III and PVY-NE11, were reported for the first time from Saudi Arabia. SYR-III is a recombinant of PVY with four RJs (Fig. 3) and shared properties with PVY ${ }^{\mathrm{NTN}}$ and PVY ${ }^{\mathrm{N}-\mathrm{Wi}_{\mathrm{i}}}$ (Chikh Ali et al. 2010a). Importantly, it was able to induce PTNRD in susceptible potato cultivars (like PVY ${ }^{\mathrm{NTN}}$ ), but unlike PVY ${ }^{\mathrm{NTN}}$, was found to have O-type serology and thus could have been erroneously typed as PVYO . SYR-III is one of the most common PVY recombinants in Syria (Chikh Ali et al. 2010a) and was recently found in Jordan (Anfoka et al. 2014). When S2 sequence was subjected to a BLASTN search through the GenBank database, an additional closely related (98\%) unpublished sequence KC903166 was found, representing a partial, 1.7-kb sequence from a tomato PVY isolate collected in 2009 in Iraq. The current report is adding Saudi Arabia to the geographic regions where SYR-III is found.

The origin of this S2 (SYR-III recombinant) isolate is unclear: AlJouf is separated from Syria by a desert, and no potato trade existed between the two countries for at least the last 10 years. There is also no potato seed trade with Jordan or Iraq, and thus, neither Jordan nor Iraq would be likely sources of the SYR-III recombinant of PVY. Considering the fact that all these countries are importing seed potatoes from other regions, SYR-III might have been introduced via imported seed tubers, which would imply a much wider distribution than had been reported so far. In the particular case of Saudi Arabia, it was established that seed potatoes were sourced from Europe. Hence it is plausible to assume that strains found in the present study were introduced from Europe given the lack of trade with neighboring countries.

The second Saudi isolate sequenced, S9, was identified as a PVYNE11 recombinant using multiplex RT-PCR and sequence analysis of the whole genome. Since it was first reported in the United States (Lorenzen et al. 2008), the incidence of PVY-NE11 had been increasing (Gray et al. 2010; Karasev et al. 2011; Karasev et al. unpublished data). Outside of the United States, a PVY isolate was described from Kalimeris indica in China with sequence sharing high identity to the

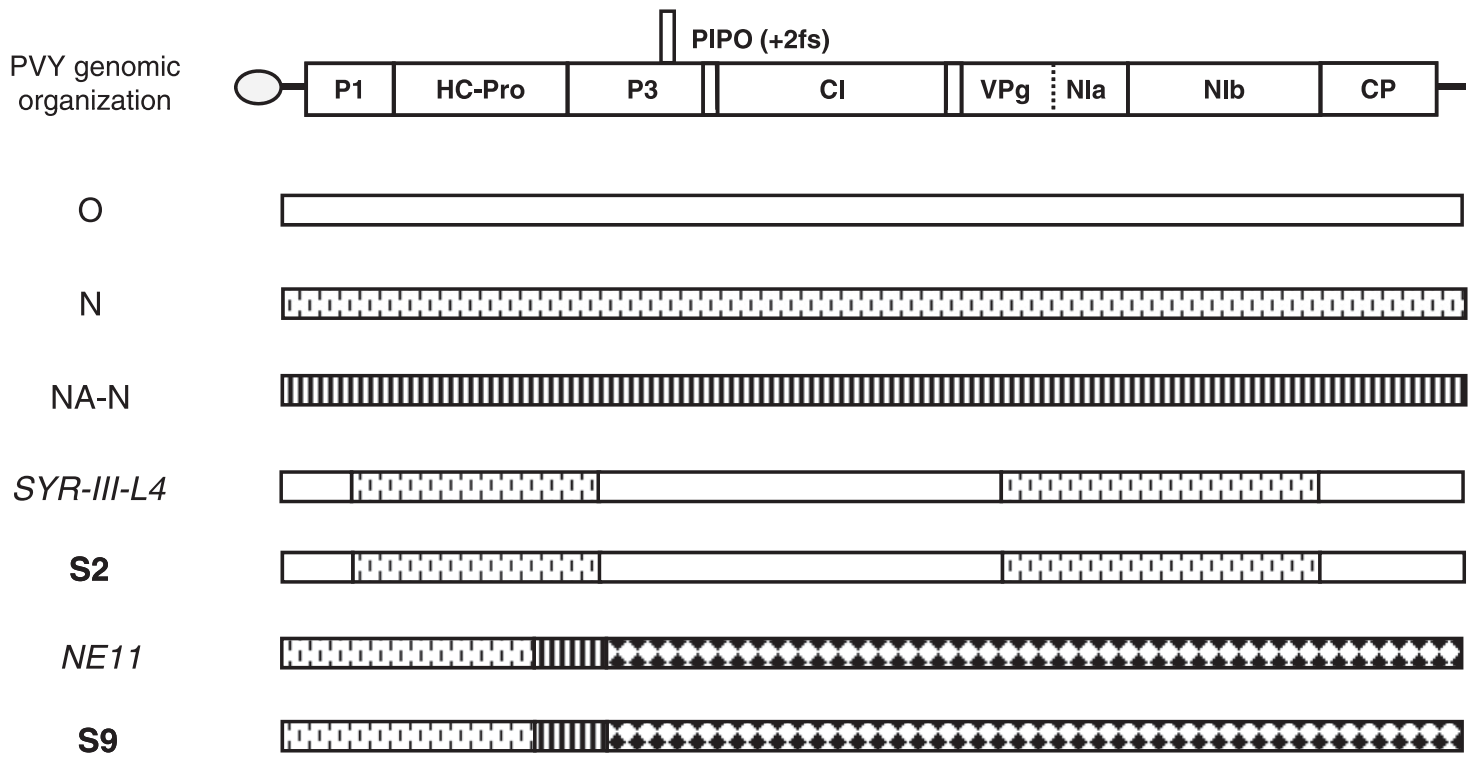

\section{$\square$ PVYO}

Fig. 3. Recombinant structure of $S 2$ and $S 9$ isolates of $P V Y$ as determined based on nucleotide sequence analysis. Rectangles designate virus genomes, and shading corresponds to the relatedness to the parental sequences, $\mathrm{PVY}$, $P \mathrm{PY}^{\mathrm{N}}, \mathrm{PVY} \mathrm{NA}^{\mathrm{N}}$, and "unknown," indicated below the diagram. The PVY genome organization is presented at the top; individual cistrons are listed, with vertical lines corresponding to polyprotein cleavage sites. The two sequenced isolates, S2 and S9, are highlighted in bold; the two reference recombinant structures, SYR-III and NE-11, are italicized. 
isolate NE-11, though it was not originally identified as a PVY-NE11 strain (GenBank accession number JQ971975; Wang et al. 2012). Thus, S9 represents the only isolate of PVY-NE11 strain found outside of the United States or China, and the first PVY-NE11 isolate found in potato anywhere outside the United States. The current finding of an NE-11 strain in Saudi Arabia also suggests that PVY-NE11 might have a wider distribution than was reported so far. PVY-NE11 has two RJs resulting in a recombinant genome with the first 2,000 nt belonging to the $\mathrm{PVY}^{\mathrm{N}}$ strain followed by a stretch of about $696 \mathrm{nt}$ of the PVY ${ }^{\mathrm{NA}-\mathrm{N}}$ strain, and the rest of the genome coming from an unknown parent of an intermediate evolutionary position between $\mathrm{N}$ and NA-N (Lorenzen et al. 2008; Fig. 2A and B). PVY-NE11 is also able to induce PTNRD (Gray et al. 2010; Lorenzen et al. 2008; Piche et al. 2004; our unpublished data). Although dry samples on the FTA cards would not allow probing the serological properties of Saudi isolates S9 (PVY-NE11) and S2 (SYR-III), the sequence analysis of the $\mathrm{S} 2$ and $\mathrm{S} 9$ genomes enabled us to predict the serotypes of these two isolates such that $\mathrm{S} 2$ would have a $\mathrm{O}$-serotype and $\mathrm{S} 9$ would have an N-serotype (Chikh-Ali et al. 2010a; Nikolaeva et al. 2012).

In conclusion, this is the first report on PVY strain typing in Saudi Arabia that revealed the existence of two significant recombinants, SYR-III and PVY-NE11. The finding of PVY-NE11 and SYR-III

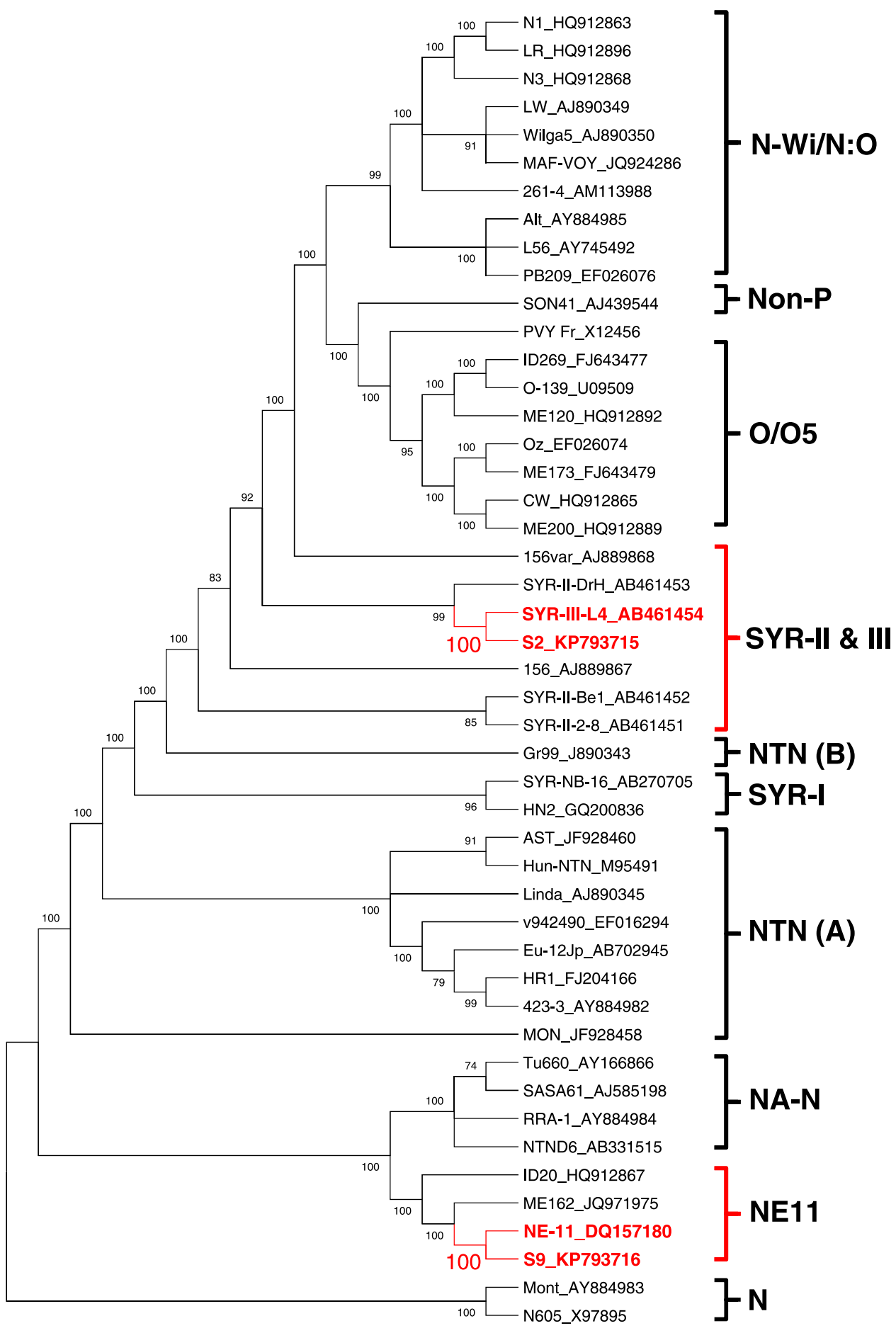

Fig. 4. Phylogenetic analysis of nucleotide sequences of the whole genomes for representative PVY isolates conducted with the neighbor joining (NJ) algorithm. Only nodes with bootstrap values higher than 70\% were retained. Brackets designate individual strains and variants of PVY according to Karasev and Gray (2013); red brackets indicate clades where S2 and S9 sequences are placed. Red colored font designates the S2 and S9 sequences paired with the closest reference sequences. Isolate name was followed by a corresponding accession number in the GenBank database. 
in a new geographic area of the Middle East suggests a broader distribution of these PVY strains than thought before (Chikh Ali et al. 2010a; Lorenzen et al. 2008). It indicates that potato producers in Saudi Arabia need to be aware of the presence of these two strains in their potato production system, since both of these strains of PVY have been previously implicated in induction of PTNRD in susceptible cultivars. It also suggests that potato seed certification agencies in countries importing seed potato should be more vigilant even toward reputable suppliers of potato seed that may inadvertently introduce PVY recombinants novel to the area.

\section{Acknowledgments}

This work was funded in part through grants from USDA-NIFA-NRI (\#200935600-05025), the Northwestern Potato Research Consortium, the Idaho State Department of Agriculture, and by the Idaho Agricultural Experiment Station. H. Alruwaili was a recipient of a graduate fellowship from the King Abdullah Scholarship Program, Saudi Arabia. D. Vander Pol was a recipient of an undergraduate INBRE fellowship supported through the NIH Grant No. P20 GM103408 (National Institute of General Medical Sciences). Authors thank Al-Jouf Agricultural Development Co., Saudi Arabia, for allowing collection of samples from one of their potato fields. Authors also thank Adel Ahmed Abdul Magd and Barjas Alruwaili for their assistance in sample collection.

\section{Literature Cited}

Adams, M. J., Zerbini, F. M., French, R., Rabenstein, F., Stenger, D. C., and Valkonen, J. P. T. 2012. Potyviridae. Pages 1069-1089 in: Ninth Report of the International Committee on Taxonomy of Viruses. A. M. Q. King, M. J. Adams, E. B. Carstens, and E. J. Lefkowitz, eds. Elsevier Academic Press, San Diego, California.

Al-Saikhan, M. S., Alhudaib, K. A., and Soliman, A. M. 2014. Detection of three potato viruses isolated from Saudi Arabia. Int. J. Virol. 10:224-234.

Al-Shahwan, I. M., Abdalla, O. A., and Al-Saleh, M. A. 1997. Viruses in the northern potato-producing regions of Saudi Arabia. Plant Pathol. 46:91-94.

Anfoka, G., Haj-Ahmad, F., Altaleb, M., Abadi, M., Abubaker, S., Levy, D., Rosner, A., and Czosnek, H. 2014. First report of recombinant Potato virus $Y$ strains infecting potato in Jordan. Plant Dis. 98:1017.

Beczner, L., Horvath, H., Romhanyi, L., and Foster, H. 1984. Etiology of tuber ringspot disease in potato. Potato Res. 27:339-352.

Boni, M. F., Posada, D., and Feldman, M. W. 2007. An exact nonparametric method for inferring mosaic structure in sequence triplets. Genetics 176: 1035-1047.

Boukhris-Bouhachem, S., Khamassy, N., Glais, L., and Kerlan, C. 2008. Occurrence in Tunisia of potato tuber necrotic ringspot disease (PTNRD) caused by variant PVY ${ }^{\text {NTN }}$ of Potato virus Y. Plant Pathol. 57:388.

Chikh-Ali, M., Gray, S. M., and Karasev, A. V. 2013. An improved multiplex IC-RT-PCR assay distinguishes nine strains of Potato virus Y. Plant Dis. 97: 1370-1374.

Chikh Ali, M., Maoka, T., Natsuaki, T., and Natsuaki, K. T. 2010a. PVY ${ }^{\text {NTN-NW }}$ a novel recombinant strain of Potato virus $Y$ predominating in potato fields in Syria. Plant Pathol. 59:31-41

Chikh Ali, M., Maoka, T., Natsuaki, K. T., and Natsuaki, T. 2010b. The simultaneous differentiation of Potato virus $Y$ strains including the newly described strain PVY ${ }^{\text {NTN-NW }}$ by multiplex PCR assay. J. Virol. Methods 165:15-20.

Chikh-Ali, M., Rowley, J. S., Kuhl, J., Gray, S. M., and Karasev, A. V. 2014. Evidence of a monogenic nature of the $\mathrm{Nz}$ gene conferring resistance against Potato virus $Y$ strain $\mathrm{Z}\left(\mathrm{PVY}^{\mathrm{Z}}\right)$ in Potato. Am. J. Potato Res. 91:649-654.

Djilani-Khouadja, F., Glais, L., Tribodet, M., Kerlan, C., and Fakhfakh, H. 2010. Incidence of potato viruses and characterization of Potato virus $Y$ variability in late season planted potato crops in Northern Tunisia. Eur. J. Plant Pathol. 126: $479-488$.

FAOSTAT. 2015. Food and Agriculture Organization of the United Nations, Statistics Division. Online: http://faostat3.fao.org

Galvino-Costa, S. B. F., dos Reis Figueira, A., Camargos, V. V., Geraldino, P. S., Hu, X.-J., Nikolaeva, O. V., Kerlan, C., and Karasev, A. V. 2012a. A novel type of Potato virus $Y$ recombinant genome, determined for the genetic strain PVY ${ }^{\mathrm{E}}$. Plant Pathol. 61:388-398.

Galvino-Costa, S. B. F., dos Reis Figueira, A., Rabelo-Filho, F. A. C., Moraes, F. H. R., Nikolaeva, O. V., and Karasev, A. V. 2012b. Molecular typing of Potato virus $Y$ isolates from Brazil reveals a diverse set of recombinant strains. Plant Dis. 96:1451-1458.

Gibbs, M. J., Armstrong, J. S., and Gibbs, A. J. 2000. Sister-scanning: a Monte Carlo procedure for assessing signals in recombinant sequences. Bioinformatics 16:573-582.
Gray, S., De Boer, S., Lorenzen, J., Karasev, A., Whitworth, J., Nolte, P., Singh, R., Boucher, A., and $\mathrm{Xu}, \mathrm{H}$. 2010. Potato virus $Y$ : an evolving concern for potato crops in the United States and Canada. Plant Dis. 94:1384-1397.

Jones, R. A. C. 1990. Strain group specific and virus specific hypersensitive reactions to infection with potyviruses in potato cultivars. Ann. Appl. Biol. 117:93-105.

Karasev, A. V., and Gray, S. M. 2013. Continuous and emerging challenges of Potato virus $Y$ in potato. Annu. Rev. Phytopathol. 51:571-586.

Karasev, A. V., Hu, X., Brown, C. J., Kerlan, C., Nikolaeva, O. V., Crosslin, J. M., and Gray, S. M. 2011. Genetic diversity of the ordinary strain of Potato virus $Y$ (PVY) and origin of recombinant PVY strains. Phytopath. 101:778-785.

Kerlan, C., and Moury, B. 2008. Potato virus Y. Pages 287-296 in: Encyclopedia of Virology, 3rd ed., vol. 4. B. W. J. Mahy and M. H. V. Van Regenmortel, eds. Elsevier, Oxford.

Kerlan, C., Nikolaeva, O. V., Hu, X., Meacham, T., Gray, S. M., and Karasev, A. V. 2011. Identification of the molecular make-up of the Potato virus $Y$

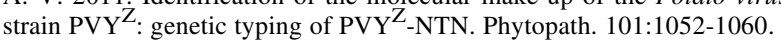

Kerlan, C., Tribodet, M., Glais, L., and Guillet, M. 1999. Variability of Potato virus $Y$ in potato crops in France. J. Phytopathol. 147:643-651.

LeRomancer, M., Kerlan, C., and Nedellec, M. 1994. Biological characterization of various geographical isolates of Potato virus $Y$ including superficial necrosis on potato tubers. Plant Pathology 43:138-144.

Lorenzen, J., Nolte, P., Martin, D., Pasche, J., and Gudmestad, N. 2008 NE-11 represents a new strain variant class of Potato virus Y. Arch. Virol. 153 517-525.

Lorenzen, J. H., Meacham, T., Berger, P. H., Shiel, P. J., Crosslin, J. M., Hamm, P. B., and Kopp, H. 2006a. Whole genome characterization of Potato virus $Y$ isolates collected in the western USA and their comparison to isolates from Europe and Canada. Arch. Virol. 151:1055-1074.

Lorenzen, J. H., Piche, L. M., Gudmestad, N. C., Meacham, T., and Shiel, P. J. 2006b. A multiplex PCR assay to characterize Potato virus $Y$ isolates and identify strain mixtures. Plant Dis. 90:935-940.

Martin, D., and Rybicki, E. 2000. RDP: detection of recombination amongst aligned sequences. Bioinformatics 16:562-563.

Martin, D., Williamson, C., and Posada, D. 2005. RDP2: recombination detection and analysis from sequence alignment. Bioinformatics 21:260-262.

Maynard-Smith, J. 1992. Analyzing the mosaic structure of genes. J. Mol. Evol. 34:126-129.

Ndunguru, J., Taylor, N. J., Yadav, J., Aly, H., Legg, J. P., Avenling, T., Thompson, G., and Fauquet, C. M. 2005. Application of FTA technology for sampling, recovery and molecular characterization of viral pathogens and virus-derived transgenes from plant tissues. Virol. J. 2:45.

Nikolaeva, O. V., Roop, D. J., Galvino-Costa, S. B. F., dos Reis Figueira, A., Gray, S. M., and Karasev, A. V. 2012. Epitope mapping for monoclonal antibodies recognizing tuber necrotic isolates of Potato virus $Y$. Am. J. Potato Res. 89 121-128.

Piche, L. M., Singh, R. P., Nie, X., and Gudmestad, N. C. 2004. Diversity among Potato virus $Y$ isolates obtained from potatoes grown in the United States. Phytopath. 94:1368-1375.

Posada, D., and Crandall, K. A. 2001. Evaluation of methods for detecting recombination from DNA sequences: computer simulations. PNAS USA 98: 13757-13762.

Sabir, J. S. M. 2012. Identification of six Potato virus $Y$ isolates from Saudi Arabia Afr. J. Biotechnol. 11:9709-9715.

Salminen, M. O., Carr, J. K., Burke, D. S., and McCutchan, F. E. 1995 Identification of breakpoints in intergenotypic recombinants of HIV type by Bootscanning. AIDS Res. Hum. Retroviruses 11:1423-1425.

Sawyer, S. A. 1999. GENECONV: a computer package for the statistical detection of gene conversion. Distributed by the Author. Department of Mathematics. Washington University, St. Louis. Available online: http://www.math.wustl. edu/ sawyer

Scholthof, K. G., Adkins, S., Czosnek, H., Palukaitis, P., Jaquot, E., Hohn, T. Hohn, B., Saunders, K., Candresse, T., Ahlquist, P., Hemenway, C., and Foster, G. 2011. Top 10 plant viruses in molecular plant pathology. Mol. Plant Pathol. 12:938-954.

Singh, R. P., Valkonen, J. P. T., Gray, S. M., Boonham, N., Jones, R. A. C., Kerlan, C., and Schubert, J. 2008. The naming of Potato virus $Y$ strains infecting potato. Arch. Virol. 153:1-13.

Tamura, K., Dudley, J., Nei, M., and Kumar, S. 2007. MEGA: Molecular Evolutionary Genetics Analysis Software Version 4. Mol. Biol. Evol. 24 1596-1599.

Thompson, J. D., Gibson, T. J., Plewniak, F., Jeanmougin, F., and Higgins, D. G 1997. The CLUSTAL-X windows interface: Flexible strategies for multiplesequence alignment aided by quality analysis tools. Nucleic Acids Res. 22: $4673-4680$

Wang, F., Wu, Y. H., Gao, Z. L., and Zhou, B. G. 2012. First report of Potato virus $Y$ in Kalimeris indica in China. Plant Dis. 96:1827. 